\title{
One Stop Government: Stalled Vision or a Matter of Design? - Empirical Findings from Social Services in Germany
}

\author{
Tino Schuppan \\ University of Applied Labor Studies, Germany \\ tino.schuppan@arbeitsagentur.de
}

\author{
Stefanie Köhl \\ IfG.CC - Institute for eGovernment, Germany \\ skoehl@ifg.cc
}

\begin{abstract}
In this paper we present selected results of a broader research project that inter alia aims at designing and specifying one stop government for parents of children with special needs facing a significantly high bureaucratic burden. Particularly, we refer to findings from two focus groups: parents of children with special needs and public administration staff. Both groups show different attitudes and perceptions towards new models of access to public services. Whereas the parents supported the designed approaches, the public administration staff rejected them. Thus, we analyze the meaning of these reactions for the design of onestop approaches as well as the ways to integrate differing attitudes and perspectives into egovernment-design. The article closes with final remarks on the usefulness of empirical-based design research, more precisely Action Design Research, in the context of e-government.
\end{abstract}

\section{One Stop Government: Stalled Vision or a Matter of Design?}

One Stop Government is probably the most wellknown e-government related model to improve access to public services. It was one of the first discussed models improving public services by the use of information technology and the implementation of front and back offices [28]. One stop shops are "providing access to public services via a single entry point even when these services are actually provided by different departments or authorities (single window)“ [50] (similar [24]). From one single electronic or physical point services of different agencies should be available in order to reduce administrative burdens for citizens. One Stop Shops seek, inter alia, to eliminate the requirement for the citizen to personally coordinate multiple tasks in order to obtain a service [3]. Over the last ten to fifteen years this approach has been vividly discussed [38], [39], [4], [29], [30], [1], [2]. Nevertheless, One Stop Government approaches in the meaning of integrating different services have been up to now hardly implemented in practice at least in Germany. Few exceptions in Germany are "Bürgerämter" (civil offices) that offer a couple of basic services such as registration services or some online service portals at Länder level (best example is Baden-Wuerttemberg), where you can directly apply for some selected public services.

Bannister/Connolly [3] stated, that one stop government and other e-government approaches are mostly stuck in vague visions of what these concepts can accomplish for transformation. They call these ideas "stalled visions" [3] based upon too generic concepts. Particularly the generic character of these concepts impedes a practical implementation. A closer connection of concepts and specific problems is needed in order to enable the implementation of one-stop government. A similar argument for the design of public service delivery makes Bertot et al. [7]. They argue that public service delivery should be both universal, i.e. independent of the recipients' social or economic status, and contextualized, i.e. able to compensate for different local needs and conditions. In particular, the last point can be extended, as it not only comes to local needs, but also to target group-specific needs. Thus, we argue that a lack of specific concepts of e-Government concretely connected to particular needs of a policy fields and specific target groups are crucial for a successful implementation. One way to incorporate these aspects is Action Research Design, i.e. empirically based design approaches that were used in the presented case.

In this article we illustrate selected empirical findings showing possible constraint factors for egovernment design of services for parents of children with special needs. In two focus group discussions carried out during the design phase parents of children with special needs and public administration staff showed different perceptions of and attitudes towards new bundled access options. Whereas the 
parents supported the design approaches, the public administration staff reacted quite defensively and negatively. We are particularly interested in the questions:

- How to explain the negative attitudes of public administration staff concerning citizen-centric one stop approaches?

- What implications do these different attitudes have for the design of one stop approaches and citizen-oriented e-government?

- How to include different attitudes and perspectives into e-government-design?

- Is the approach of Action Design Research appropriate for designing e-government?

To answer these questions we follow a twofold approach: first, a classical inductive methodological approach based upon interpretative social science concepts to analyze the focus groups. Here our interest is in how the different attitudes can be justified and interpreted. Second, a more practice oriented discussion about how these results can be used for a better or appropriate design that creates benefit and is more accepted by all stakeholders at the same time.

The paper is organized in five parts. The first part explains the methodological approaches of Action Design Research and the concrete empirical approach on the presented case with using focus groups. In the second section we introduce our analytical framework based on interpretative social research and explain the sensitizing concepts that we use to interpret our empirical results. In the third section of the article we present the empirical core-findings, especially of the focus groups. In the fourth section we discuss the implications of our results for the design of citizen- and service-oriented e-government. Finally we reflect the usefulness of Action Design Research for specific e-government concepts.

\section{Methodological Frame: Action Design Research}

\subsection{Action Design Research in general}

Action Design Research is a design method rooted in IS research, which explicitly uses empirical data for design [46]. The core idea is to combine Action Research (AR) and Design Research (DR). A quite common definition by Rapoport [45] characterizes AR as follows: "Action research aims to contribute both, to the practical concerns of people in an immediate problematic situation and to the goals of social science by joint collaboration within a mutually acceptable ethical framework." According to this definition AR has a dual goal contributing both to practice and research. The definition also assumes that persons must be involved in the research process. As a consequence, AR is highly context-dependent while attempting to address client's concerns.

For Design Science Research numerous definitions exist. Kuechler and Vaishnavi [28] characterize Design Research as "yet another "lens" or set of analytical techniques and perspectives [...] for performing research in IS. Design research involves the analysis of the use and performance of designed artifacts to understand, explain and very frequently to improve on the behaviour of aspects of Information Systems." Design research focuses on artifacts as a solution for a problem and possesses a prescriptive character [51], [33], [28], [23]. It emphasizes on how to shape IS in the most suitable manner while meeting specific requirements [17], [51]. In contrast to AR, DR assumes neither any specific client nor joint collaboration between researchers and the client.

The combination of both action and design creates a research method for generating prescriptive design knowledge through building and evaluating ensemble IT artifacts including empirical data in an organizational setting. Referring to Sein [46] it deals with two apparently disparate challenges: (1) addressing a problem situation encountered in a specific organizational setting by intervening and evaluating; and (2) constructing and evaluating an IT artifact that addresses a class of problems typified by the encountered situation. The responses demanded by these two challenges result in a method, focusing on the building, intervention, and evaluation of an artifact that reflects not only the theoretical precursors and intent of the researchers but also the influence of users and on-going use in context [46].

For e-government it is important to go beyond the design of technical artifacts and to include organizational and social aspects. E-governmentdesign has to be a socio-technical design, because humans are working with the artifacts and in the redesigned organizational structures. So design is almost about non-technical aspects and values, because otherwise IT cannot be sufficient and effective.

In simple terms, the core idea of Action Design Research is to alternate empirical research and design research in order to facilitate appropriate design concepts that are based on the actual needs of recipients. At a first glance this approach seems to be slightly innovative for e-government research. But, designed solutions do often not meet the specific needs and requirements of a target group or do not 
comprehensively consider the organizational context even if they are often based on empirical data regarding users' practices. In our experience the design of artifacts is mostly technologically driven and organizational and human factors are ignored in many cases. In our project we wanted to integrate the human factors in the design of e-government.

\subsection{Case selection and design approach}

We focused in our research on one stop government specifically designed for parents of children with special needs, because this target group is confronting a high bureaucratic burden in their interaction with public administrations. In a survey from the Dutch Ministry of Home Affairs and Kingdom Relations the effort of parents with of children with special needs to apply for benefits was estimated up to 125 hours a year [16].

Our concrete aim was to design approaches for a better access to information and services in order to reduce bureaucratic burden for parents of children with special needs. With our applied research we aim at developing a rough reference model for a sociotechnical information system supporting the cooperation between public institutions and parents of children with special needs based upon the concrete access problems of parents of those children.

Based on the idea of Action Design Research our research process included the following four empirical and design phases:

(1) Empirical investigation of the access to public services in the policy field and potentials of egovernment based solutions: We analyzed the particular needs and requirements of the target group as well as their special access problems to public services. The empirical research included document analysis (comprehensive web search of existing onestop-approaches, project reports, internal documents) and 13 qualitative interviews with parents of children with special needs (2), staff from social service providers and departments (2) and privacy policy and technical experts (9) in the end of year 2013 and beginning of year 2014 .

(2) Designing e-government solutions to improve access: In a second step we used these findings to design a one stop model meeting the actual needs of the parents and especially aiming at reducing their interaction efforts with public administrations.

(3) Empirical evaluation of the design concepts with focus groups: The aim of the subsequent evaluation phase was to discuss the design approaches as well as to validate the collected findings of the problem statement from the first empirical phase. Therefore the designed concepts were discussed in two focus groups in April 2014. Focus groups are a selected collection of individuals who discuss and comment on a specific topic, based on their personal experience [44]. Group interaction can contribute to broaden the range of responses, activate forgotten details of experience and relieve inhibitions that may discourage participants from revealing information [36]. In market research focus groups serve as a proven means to pre-test products and identify target group requirements [27]. In our context, we chose focus groups to get an insight of attitudes and opinions from different stakeholders in social services designed for children with special needs. The topics discussed concentrated on the particular problems of access to services and egovernment based one-stop solutions.

In the first focus group workshop six parents (others than in the first empirical phase) with a child with special needs discussed the findings of the empirical research and the design concepts. In a second workshop staff from public social offices, social service providers and national insurance agencies (nine participants) discussed the same topics in the same order. The discussions were protocolled by two persons and additionally recorded with an audio recorder. The recorded discussions were transcribed and inductively coded with the software NVivo.

(4) Improving design concepts based on the findings of the evaluation.

\section{Analytical Frame: Sensitizing Concepts}

Our main focus of analysis is on the public administration staffs' negative attitudes on one-stop government solutions, because this might be a barrier for citizen-oriented e-government. We apply an inductive analysis using sensitizing concepts to interpret these negative perspectives. "Inductive analysis means that the patterns, themes, and categories of analysis come from the data" [43]. Sensitizing concepts [8] give a general sense of reference and guidance in approaching empirical instances. They suggest directions along which to look [8] and provide starting points for building analysis, not ending points for evading it [15].

We inductively interpret and try to explain the different attitudes we came across resulting in three main clusters: individual-psychological perspective, socio-psychological perspective and an institutional perspective drawing on social constructivism and more concretely on ideas about institutionalization processes. 


\subsection{Individual-psychological perspective}

Individual-psychological reasons might cause the defensive attitude of the public administration staff. The focus here might be on two phenomena: "rejection of outsiders" [49] and "habituation effect". The first one deals with the rejection of possible change [42], [18], [25]. This phenomenon is based on the assumption that change proposals made up by external parties are initially blocked. The "habituation effect" describes simplifications and routinization within every day work [19]. This mostly unconscious process might generate an attitude according to the motto "We do things as we have always done!". Due to the daily work with the target group the problems of parents may be perceived as "commonplace" by the public administration staff, because once things neither appear new or special, empathy gets lost [11].

\subsection{Socio-psychological perspective}

A second possible interpretation has a sociopsychological character: Group-dynamic effects [13], [14] might drive the deconstructive attitude of the public administration staff. The process of groupdynamic interaction in focus groups affects the discussion itself and can distort the results [37]. For instance a so-called polarization effect [47] can occur where attitudes became more and more extreme during the discussion, especially when spokesmen influence the participants perception of certain issues. In our context, this approach lead us to the idea that the "negative" perspective we identified as the "public administration staffs" perspective" was in fact the subjective attitude of only one or two persons who dominated the discussion.

\subsection{Institutional perspective}

In an institutional perspective we specifically focus on social constructivism and more concretely on ideas about institutionalization processes [31], [5], [6], in particular on the bureaucratic dilemma model [22] combined with ideas of organization and system theory [32].

Social institutions are common habits of thoughts with respect to certain relationships and functions of society as well as the individual [52]. Under the guise of the "common sense" social institutions shape the way of thinking and acting in society. More specifically social institutions distinguish (sub-) systems from another [32]. Social institutions arise when actors regularly have to face a similar problem and to solve it routinely [31].

Early studies on the relation between citizens and public administration suggest that structural ambivalences in the bureaucratic system makes it difficult for members to think and interact with an orientation towards citizens [21]. The core statement of the "bureaucratic dilemma model" is: Due to conflicting goals, there is an inextricable inherent dilemma of the bureaucratic system. On the one hand the organization has to be shaped in a way that ensures equality for citizens following at the same time the rule of law and applying unified procedures to reach more efficiency. On the other hand the organization needs to be flexible in terms of citizen orientation to meet individual needs and justice [22].

Public administration staff often has strict guidelines on how to manage a case to ensure equality. Their scope to meet individual needs is often very small [20]. Additionally they have to balance internal contradictory interests (e.g. factors which boost their careers in the civil service), superiors and citizens. For instance, if costs predominate the controlling system that is the basis for employee assessment, granting less services might be an individual incentive hindering to act in a citizen oriented way.

Last but not least, the model points out that the total amount of citizens' interests is too complex for the public administration to be prepared for, especially because of the need for a clear coupling of occasion and procedure. Similar to Grunow and Hegner [20], [21], Nocke [40] claims that increasing standardization, programming and automatization narrow the scope of public administration staff and are essential reasons for the lack of citizen orientation in public administration.

These different sensitizing concepts consider institutions as basis for (in our context the public administration staffs') habits of thoughts. We analyze them in a pragmatic way: Our goal is to address to possible constraint factors for the design of concrete e-government solutions and citizen-oriented public administration. Thus, we apply the sensitizing concepts to the extent that generates useful information for design.

\section{Basic Empirical Findings}

According to our previously explained phases of research in section 2.2., we firstly present findings about the problems of access to services for parents of children with special needs to secondly introduce the design approaches we developed to solve these 
problems. Thirdly, we focus on the different attitudes found in the focus groups and further discussed in workshops.

\subsection{Problems of Access to Public Services}

We found out that the parents of children with special needs are regular users of public social services and health services due to their particular situation. For parents of children with special needs there are a huge variety of services, which are justified by the various and complex German social laws (Sozialgesetzbücher). Therefore parents of children with special needs are permanently confronted with a complex environment of public and semi-public institutions providing various services. The major problem: Not only the parents, but not even the public administration itself always know who is responsible for which services. This partly follows "switchyard" with the result that essential services are provided not or too late. Therefore coordination and cooperation between the involved institutions will not take place (cf. [26]).

Our research revealed that the reasons for the increased administrative burden are "silo structures" of public bodies, unclear responsibilities and a lack of coordination between the actors involved in the supply of services. Additional administrative burden is caused by the fact that the parents have to separately apply for each service, repeatedly submitting a large amount of personal data.

\subsection{Designed one-stop approaches}

The design approaches focused on integrating the access to information and services as well as reducing the frequency of interaction with public authorities and other organizations involved. They included an online portal integrating all relevant information and an electronic newsletter informing about current amendments. The core element was a personal (mobile) case-management giving advises and helping with applications for all services in the field. In order to reduce the amount of applications needed, we also created proactive types of service delivery to complement the one stop approaches. At a first glance this seems to be "old-fashioned", because one stop approaches are rather well-known concepts in e-government. But, as mentioned before, there is a lack of specific models for particular target groups that fit their special requirements.

\subsection{Different Attitudes - Findings from Focus Groups}

Parents of children with special needs and staff from public institutions working in that field hold very different perceptions on bureaucratic burden and service delivery. Whereas the parents claimed they have high efforts to search and apply for public services, the staff admitted parents need to make a high effort, but they estimated it as appropriate. The public administration staff pointed out that anybody needs to make efforts to apply for services. They even compared the situation of the parents with the administrative burden to apply for tax return. "Everybody would like to have an all-roundwellness-package", was one of the responses to the idea of a (mobile) case-management for the target group that coordinates the applications across all involved public, semi-public and private actors.

Several times during the discussion the public administration staff emphasized that it is the parents' duty to help themselves. They have to be the "active" part. In their opinion the parents have to search and ask for what they need instead of being served. The citizens have to visit the public administration departments, if they need support. From the public administration staffs' perspective, their own duty is primarily to grant services, if all requirements are fulfilled, not to offer them proactively. These points of view somehow match the parents complaint that the public service representatives do not adequately meet their individual needs and have too less understanding for their specific situation. This could not be expected to that extent, as it is here a social services case, from which one would have more empathy expected.

In contrast to previous findings the group of public administration staff argued that their institutions/departments intensively cooperate with each other to reduce administrative burden for the parents. However, the examples they gave to clarify their position only included types of cooperation in which they inform each other about their activities in general. Cooperation on "real cases", e.g. to help a family with an integral bunch of services were not mentioned. From the parents' point of view, it is often hard to identify which is the particular authority or institution responsible for each service in a special case since several authorities grant many different services. These "silo structures" are taken for granted and not seen as a problem by the public administration staff though they admitted that the structure of public administration departments and institutions in the field are extremely heterogeneous. They argued that the responsibilities for a particular 
service in special cases are clearly regulated by law. This is why they do not see it as a problem supposed to be solved. They rather take the silo structures for granted, assuming that they will remain or become even more differentiated in the future, because the range of services become more and more complex.

The focus groups reaction towards the presented new models of access differed. The public administration staff reacted in sum deprecating. Specifically two conflicting positions have been repeated: On the one hand, the public administration staff said that the presented concepts are more or less already existing (which, by the way, is not true), so that there is no need for them. On the other hand they pointed out a lot of reasons, why it would be difficult or almost impossible to implement them, e.g. resources, lack of qualifications of staff, etc. The parents' group discussion took a different direction. The parents appreciated the concepts for egovernment based access. They tried to concretize the ideas and made suggestions for the development of design of one stop model as well as for the improvement of the service delivery.

We resume the above-mentioned findings in three pithy theses:

(1) Parents of children with special needs estimate their effort to apply for public services as very high, whereas public administration staff perceives it as appropriate.

(2) From the perspective of the public administration staff the parents have the duty to ask for help, instead of being served.

(3) The public administration staff is used to the fragmented silo structures of public administration that constitute the main bureaucratic burden for the parents - and expect them to remain or become even more fragmented.

\section{Interpretation of the Negative Attitudes: What does it mean for Design?}

\subsection{The attempt of an explanation}

The individual- and socio-psychological perspectives presented in section 3.1. and 3.2. support in some extent the interpretation of the public administration staffs' negative attitudes towards one stop models. But we assume that there is more behind it. We go beyond this interpretation too much focused on individual perspectives gathering ideas about structural and institutional problems with citizenoriented e-government and therefore diverging from case to case. Aware of the fact that our empirical findings do not allow us to make any generalizations about the policy field and the people acting and working in it, we attempt to interpret our results going beyond the individual case.

The bureaucratic dilemma model provides some ideas about the potential reasons for the public administration staffs' attitudes regarding the efforts of parents to apply for public services and for taking the silo structures of the public administration for granted. Public servants must confront the ambivalent targets of the public administration: on the one hand, public services have to be supplied equal and efficient and on the other hand there is a need to meet citizens' individual needs. The model implies a tradeoff of values in this context: Less flexibility for citizens' needs means more equality. This dilemma is even more complicated with respect to the special target group, because more "equality" for all citizens at the same time implies discrimination for parents of children with special needs. Furthermore the bureaucratic dilemma implies that the full amount of citizens' needs is too complex to predict every request or to be only served by the public administration.

The range of services for children with special needs is very wide in Germany as well as in other welfare societies. Services range from various forms of therapies, medical and health care, technical support, hygiene products and a lot of other services supporting everyday life and participation in society. Hence, it is hard to imagine having a legal basis for all potential needs and corresponding unified procedures. That might also explain why the public administration staffs' opinion is that citizens have to ask for what they need instead of being served. The public administration staff might just be aware of the fact, that they cannot know the actual needs of every family. Additionally, the structure of public budgets might influence public administration staff's behavior: Public institutions are forced to save costs and not to exceed their budgets. Unfortunately, expenses for social or health services cannot be forecast in detail. In fact the departments are forced by law to grant applied services, if requirements are fulfilled. This area of conflict might encourage staff to a more restrictive use of resources and less proactive service orientation.

From the institutionalism perspective these "habits" to deal with conflicting goals and interests might have already become (social) institutions that permanently influence public administration staffs' behavior. Luckmann [31] claimed that habits of mind taken for granted could become institutions when they are legitimized and overtaken by others. The public administration staffs' resistant manner to "protect" public money against claims from citizens might have become a social institution in - at least 
some - public administration departments. Similarly, the silo structures taken for granted by the public administration staff might have become not only a formalized structure of the bureaucratic system, but a tight institution in the public administration culture.

Not only behavioral habits influence the way of acting. Institutions range from more informal values and norms, over more formalized guidelines for action, to juridified law [12]. In our case public administration staff have to face minimalist rules and regulations restricting what they are responsible for and allowed to do, how to proceed in a specific case and which requirements have to be met to grant a service. Germany has rigid, detailed laws for procedures in public administration and social service departments (so called Verwaltungsverfahrensgesetz (public administration procedure law) as well as "Sozialgesetzbücher" (social laws)). Services available for children with special needs are spread over a lot of different sources of law. Few people have an overview of all these services, which makes it almost impossible for only one person to give advice for the whole range of services. Some services are complementary, some overlap. The staff has no opportunity to integrate services to one proper individual offer for recipients. They only have to grant services, if requirements are fulfilled, notwithstanding effective or not. This indicates a tendency, noticed early with respect to modern types of organization: dispositive, planning parts of production processes become more and more separated from repetitive, implementing activities [40].

In relation with the use of IT this means that the work of the staff deciding about finances and service standards in the back-office is disconnected from the front-office staff. Consequently, front-office staff that at least knows better citizens' needs does not have the power to decide about citizen-oriented changes. The other way around, the back-office staff does not have the information to adequately adjust standards or variety of services. Though modern human resource management approaches have been used to reduce deskilling by so-called job enrichment, public administration clerks' area of creativity is still little extensive. This might be another interpretation option for the staff's attitudes: From their point of view there may be no good reason to understand the parents' situation, if they have anyway no power to decide how to better meet the parents needs. Their idea about their own "duty", which is to simply grant services, if requirements are fulfilled, may be driven by rigid formal institutions formalized in routine programs that affects their acting in a pre-planned way without leaving space for reflection of individual cases.

In sum, the results of our analysis show that some public administration staff has a lack of empathy with the effort that parents have to do in their application for services for their children. Furthermore, they rejected new models of access to improve the situation for the target group. Our results confirm the assumption of previous investigations that service orientation, which has been a credo in discussions about administrative modernization for a long time, has not become an integral part of the public administration culture yet. Formal as well as informal institutions influence not only the day-to-day work of the public administration staff, but also their way of thinking and acting.

\subsection{Implications for design}

For this reason we argue, that the sole design of citizen-oriented e-government artifacts is not sufficient to develop a citizen-oriented public administration. We need to consider the different perspectives and contradictions of the involved organizations, individuals as well as IT. Regarding the "human factor" the question is: How do we integrate the different attitudes towards one stop approaches in order to reach an appropriate egovernment design?

One possibility might be to just ignore the opinions of public-administration-staff. But practical experiences revealed, that this is not the best option of designing a solution that is supposed to be implemented later on in public administration. Resistance will be inevitable. The main reason for this is that the effectiveness of an e-government solution is a result of the interaction between IT, organization and actors.

Hence, to answer the question we have to go back to the very start: What is the initial goal of the design approach? In our case citizen orientation and the reduction of administrative burden is the primary goal. Thus, this should be the guiding principle of our one stop design approaches. This is why - in accordance to context factors - to integrate the perspective of the citizens is crucial for design. In our case we have firstly to adjust our artifacts to the citizens needs.

Secondly, we need to search for ways to strengthen the effect of context factors supporting our goal and weaken the effect of conflicting context factors. That means for instance that we have to explore how to design our solutions in a way that public administration staff is incentivized to act citizen oriented. One option is by creating a 
workflow management system that leads them to offer all services from different departments and institutions to the parents. From this perspective egovernment implies the improvement and development of how to achieve public goals with the use of IT considering the particular setting itself.

Ideally, for an accepted design of one-stopsolutions the different perspectives of all concerned stakeholders and context factors of the organizational settings have to be taken into account. However, this is not that easy as it sounds, because the perspectives and rationalities may be completely different as our case showed. This problem is even more complex for networked e-government: The more context factors and stakeholders are taken into account, the more complex the model becomes and the more difficulties must be considered in design approaches. At the end one stop government needs to be accepted by people working in public administration who directly confront the changes in processes and structures in their day-to-day work practices. Thus, contradicting sociological institutionalism premises an appropriate design has to be more than a desirable design.

However, e-government should not be an end in itself. The bottom line is that the overarching goal to cut red tape, in our case - has to be kept in mind for design. In contrast to this idea we argue that egovernment might be more effective not just to adapt the design of e-government to context factors of the bureaucratic system, but also to improve the bureaucratic system itself. Why to create an efficient solution within an ineffective system, when you can improve the system itself? With respect, we are aware that this is a complex and lifelong venture. But we still want to get up some rudimentary design considerations. Re-designing the system itself includes keeping away ineffective formal institutions such as social laws causing much interaction effort for citizen and a small contribution to public targets. Formal procedures have to be changed to allow social department staff to better meet individual needs. According to the bureaucratic dilemma model a balance of standardization for equality and flexibility has to be targeted to achieve citizen orientation [20]. For instance, one opportunity is to replace routine programs by specific programs oriented to the particular situations and needs that individuals confront.

Even more important than changing formal institutions is to change informal institutions. A concept of rules and regulations does not yet cause a result, but their implementation in the day-to-day practices does. Oliver [41] claims political, functional and social pressure to be the main antecedents of deinstitutionalization.
All in all we argue that to achieve citizen orientation in order to make processes more efficient it is not sufficient to just create technical design concepts. For a sustainable transformation towards a public administration in which bureaucratic burdens are reduced, it is not enough to adapt design to problematic formal and informal bureaucratic institutions. We claim for a broader design of egovernment-concepts itself, not only taking organizational, stakeholder-related and other context factors into account, but also giving impulses for system changes.

\section{Final remarks: Is ADR appropriate for e-government design?}

We conclude with the question whether the consideration of empirical data can lead to better design and hence to better implementation. Back to our initial statement that e-government is shaped by a flurry of general concepts that vanish in "real" rationalities and practices we argue that general concepts need to be translated into specified and concretized concepts that address a certain problem and consider empirical realities. ADR can contribute to reach this goal with a reflected empirical based design approach. Action Design Research, particularly its empirical ideas, can help to overcome possible implementation obstacles, e.g. resistance of public administration staff, organizational or legal circumstances. It also strengthens some kind of awareness rising within public administration staff, when confronted them with specific problems target groups have. Classical social science theories can contribute as well to interpret different attitudes towards e-government solutions and their possible reasons that should be taken into account to identify some critical points of design. Insofar as the perspectives of different stakeholders are taken into account from the very first start of the design, these theories can contribute to the acceptance and promotion of the implementation of one stop government.

At first glance the method of Action Design Research seems to be close to consulting work. But at the end, consulting work is often not oriented to a problem and too much technology-driven. The focus is on the adaptation of the problem to a given solution. We argue that specific empirical work is often missing - and therefore the special needs of target groups are not sufficiently taken into account. ADR sensitizes the perception of social aspects of design and strengthens a more socio-technical view than only technical design. Human values should be 
empirically explored in order to enable a conscious decision about their incorporation in the design (keyword: Value Sensitive Design). ADR also enables to spot problems of target groups or obstacles of implementation where you would not have suspected, e.g. question of digital divide for specific target groups that requires another design of an egovernment approach to improve public services.

In addition to that ADR can be a profitable element for co-creation and co-production. The discussion about the fact that public service innovation can be achieved through additional focus on citizen-oriented as less government-oriented aspects is not new, and has been conducted intensively in recent years [9], [10], [34], [35], [48]. Citizens or target groups as well as public administration staff could and should be the designer or co-designer [48] of one stop government or other e-government solutions in order to achieve an appropriate design that is ready for implementation and will be accepted by all involved actors. At this point we would like to stress the point of an appropriate design, not the "best" design. Of what avail is it, if a so-called best design is not implementable or accepted. This calls for a more sensitive design, which includes different stakeholder perspectives, what social sciences are responsible for. So ADR is also able to combine practical use and research interest.

We argue that e-government is an appliedoriented research that is justified on design and the implementation of artifacts. As we mentioned at the beginning of the article Action Design Research is a method for generating prescriptive design knowledge through building and evaluating IT artifacts in an organizational setting. This means to firstly address a problem situation encountered in a specific organizational setting by intervening and evaluating and secondly to construct and evaluate an IT artifact specifically addressing those problems typified by the encountered situation. Action Design Research enables to design solutions for certain problems and to use these solutions as a reference model for similar types of problems. We have shown with our special case that the design approaches for one stop government for parents of children with special needs can serve as blueprint for this particular issue in other local authorities in Germany as well as for other target groups who have similar problems with access to services. This is for instance the case with people with chronic diseases or other life situations with high bureaucratic burden (e.g. birth of a child).

A final remark: We deliberately chose an established concept to show the difficulties in design. If it already comes with a "just" transformative concept as one-stop to such difficulties, how is that right with ambitious, more disruptive approaches for the public sector? Not only for this a lot of research is mandatory.

\section{References}

[1] Aichholzer, G., R. Schmutzer, and J. Hochgerner, Bringing Public Administration Closer to the Citizens, Background Paper to the Conference of the Information society forum of the European Commission, WG 5: "Public Administration", Vienna, 12-13 November 1998

[2] Aldrich, J., J.C. Bertot and C.R. McClure, Egovernment: initiatives, developments, and issues, Government Information Quarterly, Vol. 19, Issue 4, 2002, pp. 349-355

[3] Bannister, F. and R. Connolly, Forward to the past, Lessons for the future of e-government from the story so far, Information Polity, Vol. 17. Issue 3-4, 2012, pp. 211-226

[4] Bellamy, C., I. Horrocks, and J. Webb, Exchanging information with the public: From one stop shops to community information systems, Local Government Studies, Vol. 21, Issue 1, 1995, pp. 11-30

[5] Berger, P.L. and T. Luckmann, The Social Construction of Reality: A Treatise in the Sociology of Knowledge, New York, 1966.

[6] Berger, P.L. and T. Luckmann, Die gesellschaftliche Konstruktion der Wirklichkeit, Eine Theorie der Wissenssoziologie, Frankfurt a.M., 1972.

[7] Bertot, J., E. Estevez and T. Janowski, Universal and contextualized public services: Digital public service innovation framework, Government Information Quarterly, Vol. 33, Issue 2, 2016, pp. 211-222

[8] Blumer, H., What is wrong with social theory?, American Sociological Review, Vol. 18, Issue 1, 1954, pp. 3-10

[9] Bovaird, T., Bringing the Power of the Citizen into Public Services: An Evidence Review. University of Birmingham, 2014.

[10] Bovaird, T. and E. Loeffler, From engagement to coproduction: The contribution of users and communities to outcomes and public value, Voluntas, Vol. 23, Issue 4, 2012,pp. 1119-1138

[11] Bruner, J.S. and C.C. Goodman, Value and need as organizing factors in perception, Journal of Abnormal Social Psychology, Vol. 42, Issue 1, 1947, pp. 33-44

[12] Caldwell, B., Hayek and socialism, Journal of Economic Literature, Vol. 35, Issue 4, 1997, pp. 18561890

[13] Carey M.A., The group effect in focus groups: planning, implementing and interpreting focus group research, in J. Morse (ed.), Critical Issues in Qualitative Research Methods, Thousand Oaks, 1994, pp. 225-241

[14] Carey M.A. and M. Smith M., Capturing the group effect in focus groups: a special concern in analysis, Qualitative Health Research, Vol. 4, Issue 1, 1994, pp. 123-127

[15] Charmaz, K., Grounded theory: Objectivist and constructivist methods, in N.K. Denzin and Y.S. 
Lincoln (eds.): Strategies for qualitative inquiry, Thousand Oaks, 2003, pp. 249-291

[16] Dutch Ministry of Home Affairs and Kingdom Relations, The Netherlands Regulations Country, Revised routes along administrative burdens, Den Haag, 2006.

[17] Fedorowicz, J. and M. Dias, A Decade of Design in Digital Government Research, Government Information Quarterly, Volume 27, Issue 1, 2010, pp. 1-8

[18] Furst, S.A. and D.M. Cable, Employee resistance to organizational change: Managerial influence tactics and leader-member exchange, Journal of Applied Psychology, Vol. 93, Issue 2, 2008, pp. 453-462

[19] Gibson, J.J., The Ecological Approach to Visual Perception, Boston, 1979.

[20] Grunow, D. and F. Hegner, Zum Verhältnis von kommunaler Sozialverwaltung und Publikum (1. Auflage u.d.T.: Probleme der Interaktion zwischen Verwaltung und Bürger 1974), 2. Auflage 1975, Bielefeld, 1974/1975.

[21] Grunow, D. and F. Hegner, Implikationen bürgerfernen Verwaltungshandelns für Steuerzahler und Sozialleistungsempfänger, in W. Hoffmann-Riem (ed.): Bürgernahe Verwaltung? Analysen über das Verhältnis von Bürger und Verwaltung, Darmstadt, 1980, pp.144-194

[22] Hegner, F., Das bürokratische Dilemma, Zu einigen unauflöslichen Widersprüchen in den Beziehungen zwischen Organisation, Personal und Publikum, in D. Grunow, F. Hegner and F.X. Kaufmann (eds.): Bürger und Verwaltung, Band II, Frankfurt/New York, 1987.

[23] Hevner, A., S. March, J. Park, and S. Ram, Design science in information systems research, MIS Quarterly, Vol. 28, Issue 1, 2004, pp. 75-105

[24] Ho, A.T.-K., Reinventing local governments and the egovernment Initiative, Public Administration Review, Vol. 62, Issue 4, 2002, pp. 434-444

[25] Jones, G.R., Organizational Theory, Design, and Change, Prentice Hall, 2012.

[26] Köhl, S., K. Lenk, K., S. Löbel, T. Schuppan, and A.K. Viehstädt, Stein-Hardenberg 2.0. Architektur einer vernetzten Verwaltung. Berlin, 2014.

[27] Krueger, R., Focus Groups: A Practical Guide for Applied Research, Thousand Oaks, 1994.

[28] Kuechler, B. and V. Vaishnavi, On theory development in design science research: anatomy of a research project, European Journal of Information Systems, Vol. 17, Issue 5, 2008, pp. 489-504

[29] Lenk, K. and G. Klee-Kruse, BürgerBüros als innovative kommunale Serviceagenturen, Heidelberg, 1995

[30] Lenk, K. and G. Klee-Kruse, Multifunktionale Serviceläden: ein Modellkonzept für die öffentliche Verwaltung im Internet-Zeitalter, Berlin, 2000

[31] Luckmann, T., Zur Ausbildung historischer Institutionen aus sozialem Handeln, in I. Srubar and S. Vaitkus (eds.): Phänomenologie und soziale Wirklichkeit. Entwicklungen und Arbeitsweisen, Opladen, 2002, pp. 105-115

[32] Luhmann, N., Funktionen und Folgen formaler Organisation, Berlin, 1964.

[33] March, S. and G. Smith, Design and natural science research on information technology, Decision Support Systems, Vol. 15, Issue 4, 1995, pp. 251-266
[34] Meijer, A. J., Networked coproduction of public services in virtual communities: From a governmentcentric to a community approach to public service support, Public Administration Review, Vol. 71, Issue 4, 2011,pp. 598-607

[35] Meijer, A. J., Co-production in an information age: Individual and community engagement supported by new media, Voluntas, Vol. 23, Issue 4, 2012, pp. 1156-1172

[36] Merton, R.K., E.M. Fiske, and P. Kendall, The Focused Interview: A Manual of Problems \& Procedures. Glencoe, 1956.

[37] Morgan D.L. and R.A. Krueger, When to use focus groups and why, in Morgan D.L. (ed.): Successful Focus Groups: Advancing the State of the Art, Thousand Oaks, 1993, pp. 3-19

[38] Muid, C., New Public Management and Informatisation: a natural combination?, Public Policy and Administration, Vol. 7, Issue 3, 1992, pp. 75-79

[39] Muid, C., Information systems and new public management - a view from the centre, Public Administration, Vol. 72, Issue 1, 1994, pp. 113-125

[40] Nocke, J. Bürgernähe als Qualifikationsproblem? Theoretische Voraussetzungen eines neuen Lernziels, in W. Hoffmann-Riem (ed.): Bürgernahe Verwaltung? Analysen über das Verhältnis von Bürger und Verwaltung, Darmstadt, 1980, pp. 113-139

[41] Oliver, C., The Antecedents of Deinstitutionalization, Organization Studies, Vol. 13, Issue 4, 2002, pp. 563588

[42] Oreg, S. Personality, context, and resistance to organizational change, European Journal of Work and Organizational Psychology, Vol. 15, Issue 1, 2006, pp. 73-101

[43] Patton, M. Q. Qualitative evaluation methods, Beverly Hills, 1980.

[44] Powell, R.A. and H.M. Single, Focus Groups, International Journal of Health Care, Vol. 8, Issue 5, 1996, pp. 289-303

[45] Rapoport, R.N., Three dilemmas in action research, Human Relations, Vol. 23, Issue 6, 1970, pp. 499-513

[46] Sein, M.K. et al., Action Design Research, MIS Quarterly, Vol. 35, Issue 1, 2011.pp. 37-56

[47] Sussman S., D. Burton, and C.W. Dent et al.,, Use of focus groups in developing an adolescent tobacco use cessation program: collective norm effects, Journal of Applied Social Psychology, Vol. 21, Issue 21, 1991, pp. $1772-1782$

[48] Voorberg, W., V. Bekkers and L. Tummers, A systematic review of co-creation and co-production: Embarking on the social innovation journey, Public Management Review, Vol. 17, Issue 9, 2015, pp. 1333-1357

[49] Watson, G., Resistance to Change, American Behavioral Scientist, Vol. 14, Issue 5, 1971, pp. 745-766

[50] Wimmer, M., A European perspective towards online one-stop government: The eGOV project, Electronic Commerce Research and Applications, Vol. 1, Issue 1, 2002, pp. 92-103

[51] Winter, R., Design science research in Europe, European Journal of Information Systems, Vol. 17, Issue 5, 2008, 470-475

[52] Zafirovski, M., Paradigms for analysis of social institutions: A case for sociological institutionalism, International Review of Sociology, Vol. 14, Issue 3 , 2004, pp. 363-397 